\title{
Spatial Skills Development of Engineering Students: Identifying Instructional Tools to Incorporate into Existing Curricula
}

\section{Dr. Diana Bairaktarova, University of Oklahoma}

Dr. Diana Bairaktarova is an Assistant Professor of Engineering Practice in the College of Engineering at University of Oklahoma. Through real-world engineering applications, Dr. Bairaktarova's experiential learning research spans from engineering to psychology to learning sciences, as she uncovers how individual performance is influenced by aptitudes, spatial skills, personal interests and direct manipulation of mechanical objects.

\section{Prof. Matthew Reyes, University of Oklahoma}

Matthew received his bachelor's and master's degrees from Texas A\&M University. After working for several years in the construction industry both in the field and in management, he joined the Construction Science faculty at the University of Oklahoma in 2012. His research interests include earthen construction, construction safety, and the Latino workforce in construction. He is also interested in investigating ways to teach students to improve their spatial skills and abilities.

\section{Ms. Nooshin Nassr P.E., University of Oklahoma}

Nooshin Nassr received her Bachelor of Science in Mechanical Engineering in May 2005 from Ferdowsi University of Mashhad, Iran. She is currently a PhD student in the School of Engineering at The University of Oklahoma. Her passion for engineering education stems from her basic curiosity to develop more effective engineering curriculum to help students to meet their professional demands. This motivated her to take part in engineering education research.

\section{Mr. Dan Thomas Carlton, University of Oklahoma, College of Aerospace and Mechanical Engineering}

Dan Carlton is pursuing his Bachelor's in Aerospace Engineering at the University of Oklahoma, where he is expected to graduate in 2016. He is a Midshipman in the Naval ROTC unit at the University of Oklahoma, and is involved in undergraduate fellowship program sponsored by NASA and the Oklahoma Geospatial and Space Grant Consortium. In the summer of 2014 Daniel served as a delegate for the German-American Chamber of Commerce as a part of the Transatlantic Program for Young Technology Leaders Aerospace Delegation 


\section{Identifying Motivational Factors and Lived Experiences that Enhance Spatial Skills in Novices and Experts in STEM Disciplines}

Spatial thinking refers to the ability to create and hold an object in the mind's eye and manipulate that object via sectional cuts, three dimensional rotations, and other mental operations. Literature suggest that students differ in their development of spatial skills and this difference affects student performance on some spatial tasks. Additionally, lower performance on engineering tasks involving spatial skills are observed in under-represented groups including women. In this pilot study, the first objective was to identify life experiences that predict an individual's level of spatial skills. Things such as hobbies, activities, and work experience are analyzed for predictive power along with motivational factors such as perceived instrumentality and self-efficacy beliefs. The second objective of our pilot study was to test the newly created spatial abilities predictive questionnaire. The third objective was to determine if there are differences between different STEM disciplines and working professionals.

\section{Background}

Spatial thinking refers to the ability to create and hold an object in the mind's eye and manipulate that object through cuts, rotations, etc. The underlying principles allow for spatial thinking to be utilized in solving problems that may not necessarily refer to an object. As long as one can build an accurate representation of the model problem, it can be manipulated to lead to a solution. While this can easily be seen working for macro physical objects or micro double helix patterns, it can just as well be used in fields varying from military strategy to aviation [1].The veracity that spatial thinking is paramount in STEM fields is almost self-evident. For the vast amount of scenarios in science, technology, engineering (particularly engineering), and math, problem models can be built and manipulated for solutions. For subjects that are so dependent on interaction between different objects (be in physical objects or mathematical formulas), it is paramount to be able to understand what a problem looks like and how it can be controlled.

The existing literature comprehensively covers important topics as definition of spatial skills, gender differences, spatial-skill ability and success in engineering, methods for accessing spatial skills, and recommendations for spatial skills development. The following sections provide a brief overview of the above topics in relation to spatial skills and the importance of spatial ability in STEM disciplines.

\subsection{Definition of Spatial Skills}

An important note to make is the difference between spatial "skills" and spatial "ability". The former relates to developable skills, the latter innate abilities that cannot be improved very 
well. Spatial skill refers to cognitive, perceptual, and visualization skills for objects in both 2-D and 3-D space. In the most general list, spatial skill involves the distinction between cut-away and isometric views, object rotations, and object interactions [2, 3, 4, 5, 6, 7].

Important distinction made in the literature is the distinction of spatial visualization vs. spatial relations. Spatial visualization is "the ability to imagine rotations of objects or their parts in 3-D space by folding and unfolding" [8, p.506]. Spatial relation is "the ability to imagine rotations of 2-D and 3-D objects as a whole body, which included mental rotation and spatial perception" $[8, \mathrm{p} .506]$.

\subsection{Gender Differences}

There has been a direct correlation discovered between gender and spatial thinking. The literature shows that men perform better than women in spatial perception, and women perform equally as well as men in spatial visualization $[9,10,11,12]$. There is empirical evidence that environmental factors, such as childhood leisure activities, affect spatial skills and academic performance $[13,14]$. Because of the pre-existing stereotype that men perform better spatially than women, there is such a thing as a "stereotype threat". This theory suggests that women will be less likely to outperform their male counterparts if there is the chance to confirm the stereotype that she will fail [15,16 17]. These gender differences can be greatly reduced by changing the testing environment, changing testing instructions, and providing general affirmation of their skills to women contesting men [18, 19, 20, 21, 22, 23].

\subsection{Spatial-Skill Ability and Success in Engineering}

Spatial skill is crucial for success in STEM disciplines. Studies have shown that engineering students have better spatial-skill ability than students in other disciplines. The standard and most effective assessment of spatial skills is the Purdue Spatial Visualization Test of Rotations (PVST) [9]. This test points to gender differences in spatial thinking, as well as better performance for higher subset ACT math scores and prior experience in design, building, and solid geometry [9]. Spatial skill ability is gradually becoming a standard assessment of an individual's likelihood to succeed as an engineer [24, 25, 26, 27, 28, 29]

\subsection{Methods for Assessing Spatial Skills}

Several methods of assessing spatial skills exist, but the most common ones are the DATSR, Mental Cutting Test, Vandenberg MRT, and the previously mentioned PVST. The PVST is the most widely used, but before the test can be correctly chosen, the practitioner must consider the target audience, resources available, and ability to analyze the data $[30,31,5,32,22,33,8$, 34].

\subsection{Recommendations for Enhancing Spatial Skills (Engineering Schools)}

Being that spatial skill ability is crucial to success in engineering, great care should be taken to develop these skills early on in engineering coursework and to provide expedited remedial work to those students that test low in initial assessments. Multiple schools across the country are 
a part of Engage (Engaging Students in Engineering), which works to increasing the retention rate of engineering majors [35, 36]. These schools typically offer freshman spatial courses that can be as simple and low cost as drafting or as highly refined 3-D CAD work. Whatever course of action taken is highly dependent on the student's preexisting level of spatial skill and the likelihood of a certain format succeeding which is too unique for a standardized, nationwide plan $[27,6,37,38$, $8,39,40,41]$.

\subsection{Recommendations for Enhancing Spatial Skills (Practitioners)}

While the traditional philosophy of spatial skill gaps has to do with gender differences, recent studies are pointing out that environmental factors are influential as well [17, 42, 21, 43, 44, $45,46,5]$. Factors that have been found positively impacting spatial skills include playing video games, musical experience, art, and childhood construction toys (Legos, Lincoln Logs, etc.), handeye coordination sports, and technical education. Spatial skills can be successfully developed through these means. Furthermore, most forms of kinesthetic learning are helpful as well. One important note to make is that before working on enhancing an individual's spatial skills, they must understand that spatial skill ability is not inherent but learned. This is a crucial thing to understand, because students that struggle with spatial thinking but may otherwise be academically flawless may still feel compelled to quit engineering because of a self-perceived lack of competence $[35,47,15,23,32,48,16,34]$.

\section{Purpose of the study}

The existing literature comprehensively covers the most important topics in relation to spatial skills development, improvement, and importance of these skills in STEM disciplines. In this pilot study, we first identify life experiences that predict an individual's level of spatial skills. Things such as hobbies, activities, and work experience are analyzed for predictive power along with motivational factors such as perceived instrumentality and self-efficacy beliefs. Perceived instrumentality "represents an individual's belief that performing a specific behavior will lead to a desired outcome" [50, p. 200]. Self-efficacy can be defined as an individual's beliefs about their competence with reference to a certain task. While the individual's actual level of competence inevitably plays a role in the amount of self-efficacy that he will have, this is not what is at the heart of analyzing the impact of self-efficacy. Psychologist Albert Bandura noted that, "perceived self-efficacy is concerned not with the number of skills you have, but with what you believe you can do under a variety of circumstances" [51, p. 37]. While these facets of motivation have been well established, there is a lack of reliable spatial ability predictive instrument when it comes to motivational factors. The second objective of our pilot study is to test the newly created spatial abilities predictive questionnaire and then to determine if there are differences between different STEM disciplines and the profession across.

In addition to the two main goals of this study we hypothesized that based on the curriculum and work experiences, experts (professionals and graduate students) would have higher spatial skills than the junior and senior students, respectively junior and senior students will have higher spatial skills than freshman engineering students. 


\section{Method}

\subsection{Data Collection}

Data was collected from four groups at different levels of their studies and lives: first year engineering (FYE) students ( $\mathrm{N}=120)$, junior and senior mixed majors - Aerospace Engineering, Electrical Engineering, Mechanical Engineering, and Construction Science students $(\mathrm{N}=120)$, graduate engineering students $(\mathrm{N}=20)$, and practicing engineers $(\mathrm{N}=29)$. The study was conducted at The University of Oklahoma in the Fall 2014 semester. The students' participants completed an online survey as part of class activity in engineering design related courses. The Electrical engineering and Construction Science students completed the survey for a class credit. A link with the online survey was sent to the graduate students and the professionals participants. The last two groups of participants were selected using convenient sampling. Both groups were from the researchers networks.

The survey was identical for all participants. It contained Revised Purdue Spatial Visualization Tests: Visualization of Rotations (PSVT:R) [49]. The PSVT:R test was utilized to measure the cognitive portion regarding students' spatial reasoning skills. To measure the affective portion, all participants completed a survey with some demographic items, motivation items, and questions about childhood and life experiences. The instrument was inspired by previous work by Sorby and Veurink [52] that looked into student background. For this study, researchers sought to build upon this prior work and create a comprehensive instrument that includes motivational items such as perceived instrumentality and self-efficacy beliefs. We must note that this pilot study also served to test the instrument. Future studies will gather data regarding prior training related to spatial visualization skills.

\subsection{Data Analysis:}

To analyze the findings from the self-report questions, exploratory factor analysis (EFA) was used with the measures of motivational factors such as perceived instrumentality and selfefficacy beliefs. Based on the literature, we expected that individuals who were exposed in their early childhood and later on in live to experiences related to the manipulation of objects via sectional cuts, three dimensional rotations, and other mental operations will have higher performance score on the PSVT:R. We also expected that individuals who believed that they are good at spatial reasoning and spatial reasoning is important for their success in their field will perform better on the PSVT:R. To test if there is a difference in score between the activities based on the perceived instrumentality and self-efficacy beliefs, we utilized ANOVA test.

ANOVA test was performed to test if there are statistical differences in score on the variables of major; the variable of novices vs experts (freshman students, junior and senior students, graduate students, and professionals); the variables of gender and ethnicity.

Correlation analysis was utilized to test relationship between age and PSVT:R score, Motivation and PSVT:R score. The motivation score correlation was carried out on the score as a whole and also with the self-efficacy and perceived instrumentality scores separated. 


\section{Findings}

Statistical analyses were carried out to test hypotheses related to the previously stated items. The primary objective of all the analyses was to examine how various factors (age, gender, ethnicity, student classification, experience, college major, and motivational factors) impacted individuals' spatial ability. Demographic information was tested first. The result was that the males scored approximately 2.5 points higher than the females, a difference that was statistically significant at the $\mathrm{p}=0.001$ level. The descriptive statistics are shown in Table 1 .

Table 1: Descriptive statistics with scores by gender

\begin{tabular}{|rl|r|r|r|r|}
\hline & Gender & \multicolumn{1}{c|}{$\mathrm{N}$} & \multicolumn{1}{c|}{ Mean } & Std. Deviation & Std. Error Mean \\
\hline \multirow{2}{*}{ PSVT:R Score } & Male & 173 & 21.58 & 5.050 & .384 \\
& Female & 77 & 19.10 & 5.310 & .605 \\
\hline
\end{tabular}

Further mean comparisons were done by way of ANOVA for variables with multiple levels. The analysis showed that there is no statistical difference between any of the groups tested. On the factor of spatial ability (PSVT:R score), there is no statistical difference found when the data are grouped by ethnicity, college major, or student classification. There is a difference in means but even at the $\mathrm{p}=0.10$ level there is no statistical significance. The mean scores, including standard deviation bars, for each group are plotted in Figures 1, 2, and 3.

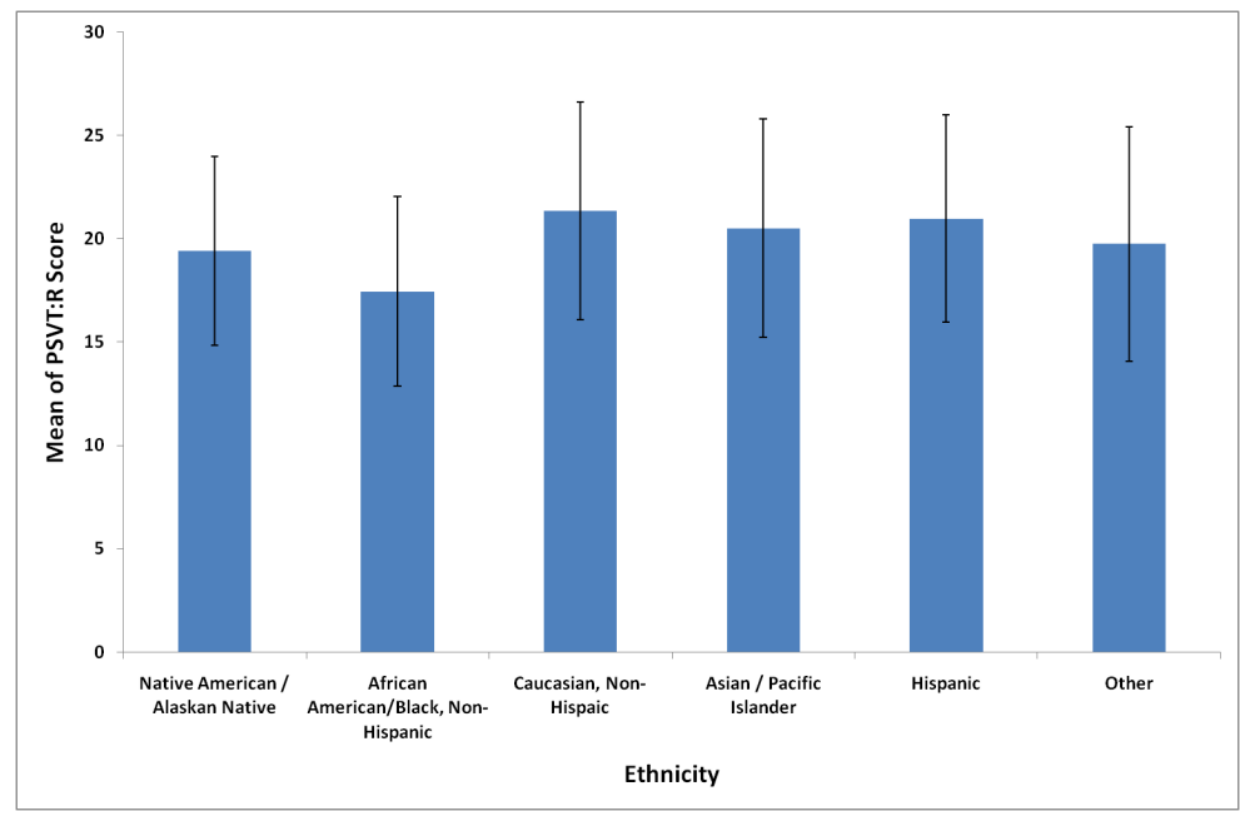

Fig. 1: PSVT:R score by ethnicity 


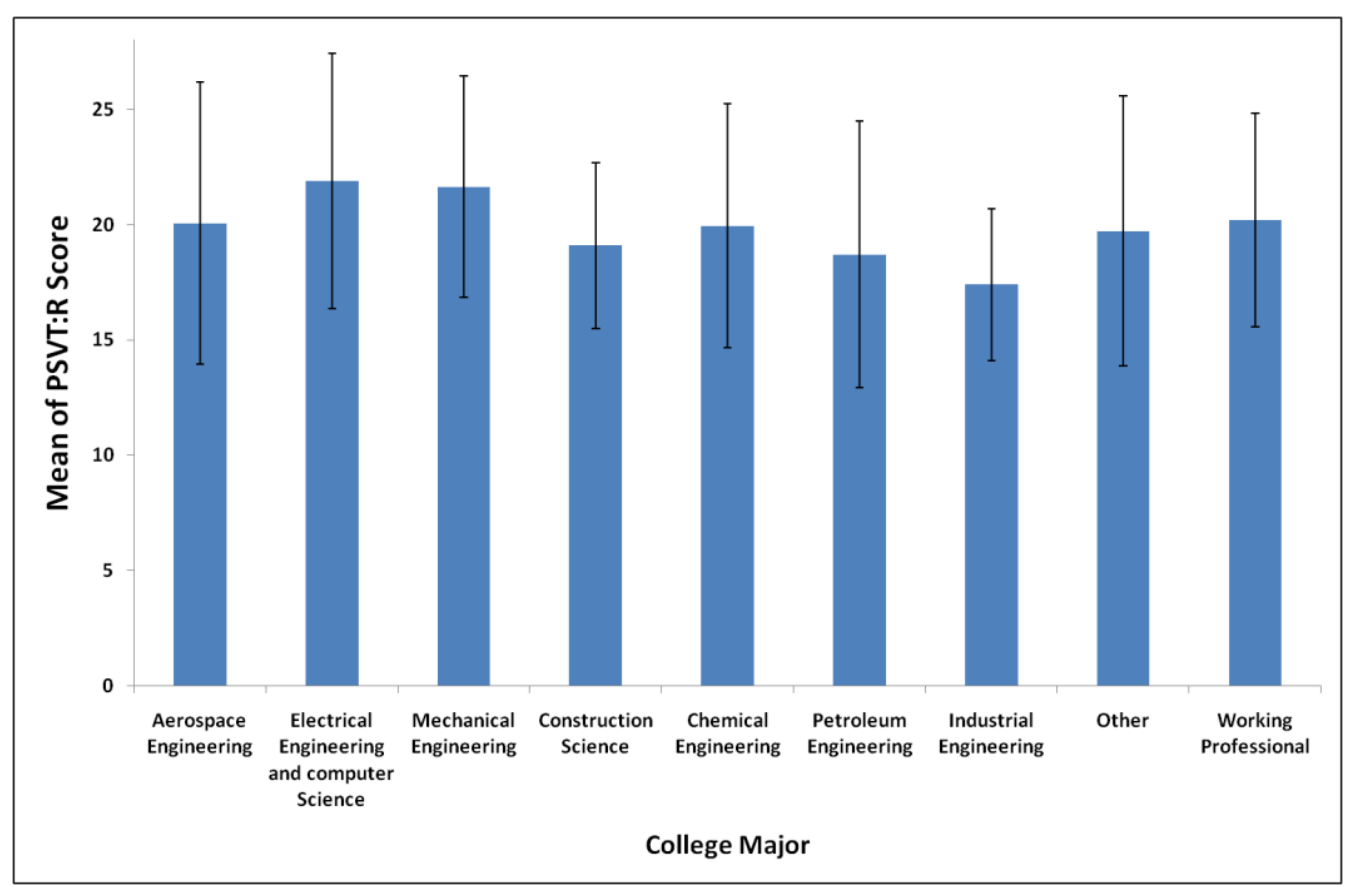

Fig 2: PSVT:R score by college major

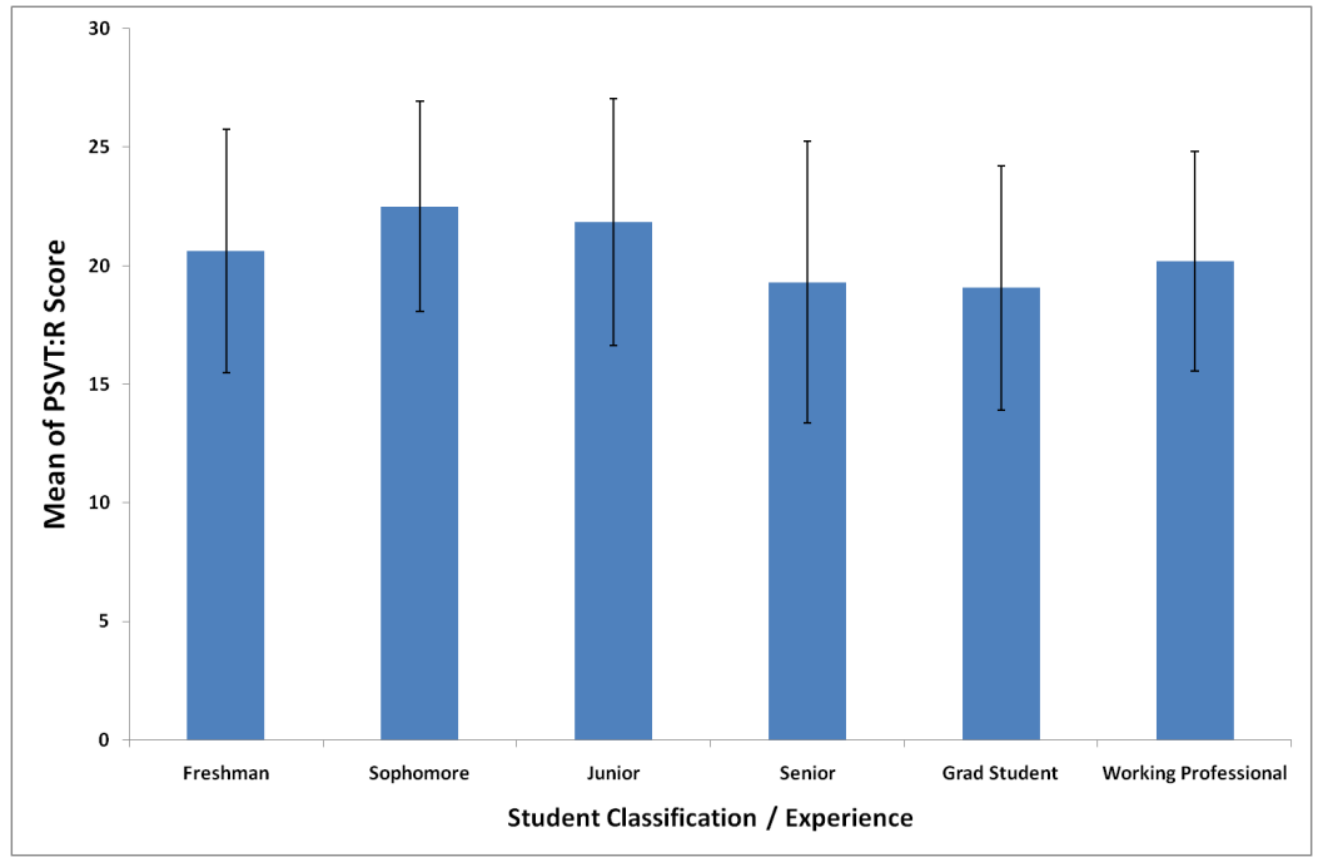

Fig 3: PSVT:R score by student classification / experience

To examine an additional experience factor, a correlation analysis was carried out on individuals' age as it related to PSVT:R score. A Pearson correlation test revealed that there is no statistically significant correlation between age and PSVT:R score. 
To examine the impact of motivation on PSVT:R score, additional Pearson correlation analyses were carried out on the motivational scores as related to PSVT:R score. The whole motivation scores were found to correlate with PSVT:R scores at $r=0.219$ with a $p$-value of 0.001 . The perceived instrumentality and self-efficacy scores were divided and Pearson correlation analyses were carried out on them individually. Results were that the perceived instrumentality scores did not correlate at a statistically significant level $(\mathrm{p}=0.321)$. However, after removing the perceived instrumentality scores, the self-efficacy yielded slightly more powerful results. Selfefficacy scores correlated with PSVT:R scores at $r=0.259$ with a p-value less than 0.001 . Correlations are summarized in Table 2.

Table 2: Correlation matrix of motivational factors and PSVT:R scores

\begin{tabular}{|l|c|c|}
\hline & $\begin{array}{c}\text { PSVT:R } \\
\text { Score }\end{array}$ & p-value \\
\hline Total Motivation Scores & 0.219 & 0.001 \\
\hline Perceived Instrumentality Scores & 0.066 & 0.321 \\
\hline Self-Efficacy Scores & 0.259 & $<0.001$ \\
\hline
\end{tabular}

As part of this study, a preliminary investigation was done into how individuals' life experiences and activities impact spatial ability. This was done through an exploratory factor analysis. There were 17 variables regarding life experiences and activities. The factor analysis indicated that there were five factors with eigenvalues greater than 1.0. After analyzing the results, a more appropriate number of factors was likely four as the fifth factor had an eigenvalue quite a bit lower than the fourth factor (1.2 and 1.8). At this stage of development of the study, it appears as though a four factor model is the most appropriate. Likely categories include Played Video Games, Played Sports, Participated in Art and Music, and Worked with Hands.

\section{Discussion and Next Steps}

The primary findings of this study indicate that there are differences among individuals on their spatial ability on the variable of gender but differences were not found on other variables such as student classification, experience, and college major. It should be noted that all individuals were in STEM fields. Future research will include a larger variety of specialties to analyze individuals in non-STEM fields. There were also differences identified on the factor of age and ethnicity. Motivational factors, particularly self-efficacy, correlated with individuals' scores. Further research will focus on exactly how this impacts spatial ability and what the source is.

The analysis of how lived experiences and activities impact spatial ability is still underway. Researchers hypothesize that these will serve as intervening variables between independent variables and spatial abilities, particularly gender. Particularly as it relates to the role of gender, the findings of our pilot study are consistent with the literature. However, we will focus our future research on studying possible intervening variables such as lived experiences of individuals that serve to impact an individual's spatial ability. We expect that this analysis to be the most impactful 
in the future as the lived experiences that impact spatial ability can be translated into instructional interventions that can be applied in existing curricula in STEM disciplines.

\section{Conclusion}

We trust our study will inform engineering education community in two ways: 1). Gaining a deeper insight on the intrinsic relationships between spatial thinking and STEM disciplines. 2). Findings from this study can lead to clues on how to integrate elements of spatial thinking with engineering concepts and incorporating teaching spatial skills with courses in the existing pre-engineering and engineering curriculum.

\section{Bibliography}

[1] Bodner, G. \& Guay, R. (1997). The Purdue Visualization of Rotations Test. The Chemical Educator. 2(4), 5-7.

[2] McGee, M. G. (1979). Human spatial abilities: Psychometric studies and environmental, genetic, hormonal, and neurological influences. Psychological Bulletin, 86, 889-918.

[3] Pellegrino, J., Alderton, D., \& Shute,V. (1984). Understanding spatial ability. Educational Psychologist, 19(3), $239-53$.

[4] Clements, D. H., \& Battista, M. T. (1992). Geometry and spatial reasoning. In D. Grouws (Ed.), Handbook of research on mathematics teaching and learning, pp. 420-64. New York, NY: Macmillan Publishing Company.

[5] Sorby, S. A. (1999). Developing 3D spatial visualization skills. Engineering Design Graphics Journal, 63(2), 21-32.

[6] Olkun, S. (2003, April). Making connections: Improving spatial abilities with engineering drawing activities. International Journal of Mathematics Teaching and Learning, 1-10.

[7] Sutton, K., \& Williams, A. (2008). Developing a discipline-based measure of visualization. UniServe Science Proceedings, 115-20.

[8] Martín-Dorta, N., Saorín, S. J., \& Contero, M. (2008). Development of a fast remedial course to improve the spatial abilities of engineering students. Journal of Engineering Education, 97(4), 505-13.

[9] Guay, R. B. (1977). Purdue Spatial Visualization Test: Rotations. West Lafayette, IN: Purdue Research Foundation.

[10]Masters, M. S., \& Sanders, B. (1993). Is the gender difference in mental rotation disappearing? Behavior

Genetics, 23(4), 337-41.

[11] Hamilton, C.J. (1995). Beyond sex differences in visuo-spatial processing: The impact of gender trait possession. British Journal of Psychology, 86(1), 1-20.

[12] Moe, A. (2009). Are males always better than females in mental rotation? Exploring a gender belief explanation. Learning and Individual Differences, 19(1), 21-7.

[13] McGee, M. G. (1979). Human spatial abilities: Psychometric studies and environmental, genetic, hormonal, and neurological influences. Psychological Bulletin, 86, 889-918.

[14] Immekus, J. C., \& Maller, S. J. (2010). Factor structure invariance of the Kaufman Adolescent and Adult Intelligence Test across male and female samples. Educational and Psychological Measurement, 70, 91-104.

[15]Levine, S. C., Vasilyeva, M., Lourenco, S. F., Newcombe, N. S., \& Huttenlocher, J. (2005). Socioeconomic status modifies the sex difference in spatial skill. Psychological Science, 16(11), 841-45.

[16] Hill, C., Corbett, C., \& St. Rose, A., (2010). Why so few? Women in science, engineering technology and mathematics. Washington, DC: AAUW.

[17] Linn, M. C., \& Petersen, A.C. (1985). Emergence and characterization of sex differences in spatial ability: A metaanalysis. Child Development, 56(6), 1479-98.

[18]Linn, M. C., \& Petersen, A. C. (1986). A meta-analysis of gender differences in spatial ability: Implications for mathematics and science achievement. In J. S. Hyde \& M. C. Linn (Eds.), The psychology of gender: Advances through meta-analysis (pp. 67-101). Baltimore, MD: Johns Hopkins University Press.

[19] Sharps, M. J., Welton, A. L., \& Price, J. L (1993). Gender and task in the determination of spatial cognitive performance. Psychology of Women Quarterly, 17, 71-83. 
[20] Sharps, M. J., Price, J. L., \& Williams, J. K. (1994). Spatial cognition and gender: Instructional and stimulus influences on mental image rotation performance. Psychology of Women Quarterly, 18, 413-25.

[21] Bergvall, V. L., Sorby, S. A., \& Worthen, J. B. (1994). Thawing the freezing climate for women in engineering education: Views from both sides of the desk. Journal of Women and Minorities in Science and Engineering, 1, 323-46.

[22] Contero, M., Naya, F., Company, P., \& Saorín, J. L. (2006). Learning support tools for developing spatial abilities in engineering design. International Journal of Engineering Education, 22(3), 470-77.

[23] Feng, J., Spence, I., \& Pratt, J. (2007). Playing an action video game reduces gender differences in spatial cognition. Psychological Science, 18(10), 850-55.

[24] Miller, C. L., \& Bertoline, G. R. (1991). Spatial visualization research and theories: Their importance in the development of an engineering and technical design graphics curriculum model. Engineering Design Graphics Journal, 55(3), 5-14.

[25] Humphreys, L. G., Lubinski, D., \& Yao, G. (1993). Utility of predicting group membership and the role of spatial visualization in becoming an engineer, physical scientist, or artist. Journal of Applied Psychology, 78(2), 250-61.

[26] Peters, M., Chisholm, P., \& Laeng, B. (1994). Spatial ability, student gender, and academic performance.

Journal of Engineering Education, 83(1), 1-5.

[27] Hsi, S., Linn, M. C., \& Bell, J. E. (1997). The role of spatial reasoning in engineering and the design of spatial instruction. Journal of Engineering Education, 86(2), 151-58.

[28] Webb, R. M., Lubinski, D., \& Benbow, C. P. (2007). Spatial ability: A neglected dimension in talent searches for intellectually precocious youth. Journal of Educational Psychology, 99(2), 397-420.

[29] Sorby, S. A. (2009). Educational research in developing 3!D spatial skills for engineering students. International Journal of Science Education, 31(3).

[30] Eliot, J., \& Smith, I. M. (1983). An international directory of spatial tests. Windsor, Berkshire, UK: NFER-NELSON Publishing Company. (Out of print; available at http://drc.ohiolink.edu/handle/2374.OX/30660)

[31] Voyer, D., Voyer, S., \& Bryden, M. P. (1995). Magnitude of sex differences in spatial abilities: A meta-analysis and consideration of critical variables. Psychological Bulletin, 117(2), 250-70.

[32] Sorby, S. A. (2007). Developing 3D spatial skills for engineering students. Australasian Journal of Engineering Education, 13(1), 1-11.

[33] Németh, B. (2007). Measurement of the development of spatial ability by mental cutting test. Annales Mathematicae et Informaticae, 34, 123-8.

[34] Sorby, S. A., \& Veurink, N. (2010). Are the visualization skills of first-year engineering students changing? Proceedings of the $117^{\text {th }}$ ASEE Conference and Exposition.

[35] Metz, S.S., Sorby, S.A., Berry,T., Seepersad, C., Dison, A.M., Allam, Y., Merrill, J., Peters,W., PfisterAltschul, E., Baxter, S., Zhang, G., and Leach, J. (2011). Implementing Strategies to Improve Retention: Focus on Spatial Skills-Engineering Schools Discuss Successes and Challenges. Proceedings of the $118^{\text {th }}$ ASEE Conference and Exposition.

[36] Sorby, S. A., (2011, January 27). ENGAGE webinar: Improving spatial visualization skills. Retrieved from http://www.engageengineering.org/?page=26.

[37] Sorby, S. A., \& Baartmans, B. J. (2000). The development and assessment of a course for enhancing the 3 !D spatial visualization skills of first year engineering students. Journal of Engineering Education, (89)3, 301-7.

[38] Sorby, S. A., Drummer, T., Hungwe, K., Parolini, L., \& Molzan, R. (2006). Preparing for engineering studies: Improving the 3D spatial skills of K-12 students. Proceedings of the 9th International Conference on Engineering Education, T3E-6-T3E-10.

[39] Onyancha, R., Towle, E., \& Kinsey, B. (2007). Improvement of spatial ability using innovative tools: Alternative view screen and physical model rotator. Proceedings of the 114th ASEE Conference and Exposition.

[40] Ferguson,C., Ball,A., McDaniel,W., \& Anderson, R. (2008). A comparison of instructional methods for improving the spatial-visualization ability of freshman technology seminar students." Proceedings of the IAJCIJME International Conference.

[41] Onyancha, R. M., Derov, M., \& Kinsey, B. L. (2009). Improvements in spatial ability as a result of targeted training and computer-aided design software use: Analyses of object geometries and rotation types. Journal of Engineering Education, 98(2), 157-67.

[42] Baenninger, M., \& Newcombe, N. (1989). The role of experience in spatial test performance: A meta-analysis. Sex Roles, 20(5/6), 327-44. 
[43] Deno, J. A. (1995). The relationship of previous experiences to spatial visualization ability. Engineering Design Graphics Journal, 59(3), 5-17.

[44] Vasta, R., Knott, J. A., \& Gaze, C. E. (1996). Can spatial training erase the gender differences on the waterlevel task? Psychology of Women Quarterly, 20, 549-67.

[45] Lord, T. R., \& Garrison, J. (1998, June). Comparing spatial abilities of collegiate athletes in different sports. Perceptual Motor Skills Journal, 86(3, Pt. 1), 1016-8.

[46] Caldera, Y. M., Culp, A. M., O’Brian, M., Truglio, R. T., Alvarez, M., \& Huston, A. C. (1999). Children's play preferences, construction play with blocks, and visual-spatial skills: Are they related? International Journal of Behavioral Development, 23(4), 855-72.

[47] Robichaux, R. (2002). Predictors of spatial visualization: Structural equations modeling test of background variables. Journal of Integrative Psychology, 2(2).

[48] Hand, L. L, Uttal, D. H., Marulis, L., \& Newcombe, N. S. (2008). A meta-analysis of training effects on spatial skills. Presented at the annual meetings of the Association for Psychological Science, Chicago.

[49] Maeda, Y., \& Yoon, S. Y. (2011). Scaling the Revised PSVT-R: Characteristics of the first year engineering students' spatial ability. In Proceedings of the American Society for Engineering Education (ASEE) Annual Conference and Exposition, 2011-2582, Vancouver, BC, Canada.

[50] Chiaburu, D. S. \& Lindsay, D. R. (2008). Can do or will do? The importance of self-efficacy and instrumentality for training transfer. Human Resource Development International, 11(2), 199-206.

[51] Bandura, A. (1997). Self-efficacy: The exercise of control. New York: W. H. Freeman and Company.

[52] Sorby, S. \& Veurink, N. (2012). Spatial skills among minority and international engineering students. Proceedings of the 119th ASEE Conference and Exposition. 